http://dx.doi.org/10.5007/2175-795X.2012v30n2p657

\title{
Ações políticas educacionais e impactos sobre o trabalho docente
}

Alda Junqueira Marin*

\section{Resumo}

O artigo apresenta análises sobre a Lei no 9.394/1996 que estabelece as diretrizes e bases da educação nacional e os seus desdobramentos que pressupóem várias mudanças para as escolas e para o trabalho dos professores. Afirma esse agente como sujeito às açôes políticas em educação e aponta a necessidade de compreensão ampla com relaçôes entre diferentes aspectos tanto na pesquisa quanto para a formação e para o exercício da função nas escolas. Para tanto, examina pontos da organização do trabalho e da organização da escola presentes na legislação e seus impactos sobre o trabalho dos professores, articulando com dados de pesquisas atuais.

Palavras-chave: Diretrizes da Política Educacional. Organização do Trabalho Docente. Problemática do Magistério.

\footnotetext{
* Doutora em Ciências da Educação pela Faculdade de Filosofia Ciências e Letras de Rio Claro, atual Universidade Estadual Paulista (UNESP). Professora Livre-Docente aposentada da UNESP, atualmente professora e pesquisadora da Pontifícia Universidade Católica de São Paulo (PUC/SP).
} 


\section{Introdução}

Os estudos mais recentes que temos feito sobre o trabalho docente nos levam a detectar que os professores e seu trabalho, nas escolas, têm estado sob intenso fogo cruzado ao longo das últimas décadas. Isso é perceptível nos estudos, nas manifestações oficiais, na mídia e até mesmo no dia a dia, com todos os agentes das escolas, muitas reclamaçôes, muitos comentários, insatisfaçôes de parte a parte.

Essa situação vigente, há tempos, tem levado muitos pesquisadores a dedicar-se a tal tema - o trabalho docente. Em estudo que fizemos no início da década de 2000 (MARIN; BUENO; SAMPAIO, 2005), levantamos dados relativos a pesquisas sobre a escola, só no âmbito do Ensino Fundamental, verificando que os estudos sobre professores já eram um dos focos mais importantes na área da educação quando se considera o período de 1981 a 1998. O levantamento abrangeu resumos de teses e dissertaçóes dos cursos de pós-graduação, que são os loci mais importantes em matéria de realização de pesquisas educacionais no País. Verificamos que $29 \%$ das pesquisas feitas foram sobre professores. Pesquisava-se mais sobre professores do que sobre a escola propriamente dita, sobre saberes e sobre alunos. Esses outros focos também eram do nosso interesse, porém, aqui se destaca que esse dado percentual é importante porque permite confirmar a noção de que há muitos anos se pesquisa sobre professores, e não obtendo destaque acadêmico apenas nos últimos anos.

Nesse período citado, desdobrando o foco dos professores em dois temas, verificou-se que o tema da prática docente foi um pouco mais frequente do que o tema da formação docente com posterior crescimento numérico. Em outro levantamento para um período mais alargado, atingindo de 1987 a 2006, abrangemos quase uma década a mais de informaçóes, obtendo o significativo total de 417 estudos de dissertaçóes e teses realizadas no País especificamente sobre o tema do trabalho docente, significando grande aumento em relação aos outros temas anteriores, ou seja, 84 estudos sobre formação docente, por exemplo (MARIN; BUENO, 2010).

Esses levantamentos foram feitos a partir do site da Coordenadoria de Aperfeiçoamento do Pessoal do Ensino Superior (CAPES), portanto, dados oficiais. No que tange especificamente ao tema "trabalho docente", verificamos que havia baixa incidência de estudos até meados dos anos de 1990, mais exatamente até o ano de 1995, cerca de 40 desses estudos aliando o trabalho 
à formação. Essa relação se altera a partir de então. Essa marca temporal é significativa? Por quê?

Os estudiosos da área da História nos ensinam que só podemos ter marcos de temporalidade quando encontramos algum elemento de mudança que seja significativo. Para a equipe que fez esse trabalho, foi considerado marco significativo, porque a formação docente, que já vinha sendo estudada em si mesma, começou a ficar relacionada com o trabalho docente. Foi nesse momento que percebemos, pelo levantamento ano a ano, que começou a haver uma ligação forte entre a formação docente e o trabalho docente, o que não havia anteriormente. Portanto, esse marco de temporalidade é um elemento significativo na produção da área nos cursos de pós-graduação, ou seja, na pesquisa brasileira.

Esse levantamento permitiu que detectássemos a existência de algumas dificuldades nessa evolução, quando se analisa a existência ou não de acúmulo de informação. Em primeiro lugar, verifica-se dispersão temática: estuda-se trabalho docente relacionado a muitos assuntos, sem haver densidade a ponto de haver acúmulo de informação sobre os assuntos. Também há dispersão no âmbito da escolaridade focalizada. No segundo bloco de levantamento, detectamos maior índice de estudos não só temporalmente, mas abordamos o trabalho docente nas diferentes esferas educacionais. Enquanto no primeiro levantamento a esfera focalizada foi o Ensino Fundamental, no segundo a esfera abrangeu desde a Educação Infantil até o Ensino Superior, para se ter um espectro mais amplo sobre os estudos sobre esse tema no País. Verificou-se, assim, que há dispersão de estudos no que diz respeito ao âmbito da escolaridade analisado: foram estudados todos os âmbitos, o que nos pareceu um interesse positivo, de um lado, e de outro é sinal de problemas detectados pelos pesquisadores nos dois níveis de ensino brasileiros.

Dispersão também ocorreu devido às orientaçôes. Identificou-se que havia 345 estudos com orientadores identificados, os mais diferentes, inclusive estudos sem definição de orientação. 286 desses estudos foram orientados, cada um deles, por pesquisadores diferentes, ou seja, 286 estudos com 286 orientadores, num total de $82 \%$ das pesquisas. Apenas dois orientadores acompanharam cinco trabalhos. Isso levou a analisar o significado do ponto de vista da distribuição de informação e, consequentemente, dispersão no que diz respeito à orientação teórico-metodológica. Ou seja, existem fundamentos os mais variados para estudar o trabalho docente. 
Esses dados permitiram extrair a informação de que há um debate acadêmico instalado sobre o tema do trabalho docente. Do ponto de vista acadêmico, e do ponto de vista das consequências que isso possa ter para políticas e para a melhoria das escolas de um lado, é bastante sério. De outro lado, demonstra um tema em plena evolução, um objeto de estudo em construção. Significa que um esforço feito por grupos de pesquisa articulados tem grande relevância, pois pesquisando as mesmas questôes possibilita esse acúmulo necessário, até mesmo para regiốes em que essa informação não está disponível.

Diante desse quadro ainda fragmentado, este texto constitui uma pequena contribuiçáo a partir de estudos dos últimos anos, exatamente para tentar verificar se conseguimos densidade maior de informações, e que isso possa trazer ampliação analítica sobre o tema.

Adentrando um pouco as especificaçóes iniciais: escrever, estudar e analisar o trabalho dos professores cada vez se torna mais relevante para ampliar a compreensão, principalmente quando o estudo ocorre no interior das escolas e a partir delas. Trata-se de relevância acadêmica, como já foi apontado, mas destacadamente há relevância política, porque são milhões e milhōes de alunos e professores envolvidos com essa atividade que é a atividade da docência, de ensino e de aprendizagem, conforme as estatísticas oficiais. Trata-se do maior contingente humano agregado em torno de uma atividade profissional. É a partir das informaçóes que obtivermos sobre eles que poderemos ter melhores professores formados, melhores alunos formados, delineando alternativas para melhoria da educação.

São apresentadas, na sequência, algumas bases para as análises e alguns dados relacionando açóes políticas e as consequências para o trabalho dos professores.

\section{Algumas bases para análise}

O que se apresenta como base, como pano de fundo?

Em primeiro lugar, é a realidade brasileira de onde foram extraídos esses exemplos, a partir de trabalhos de pesquisa já encerrados, mas articulados em projetos coletivos em andamento, um deles sob minha coordenação, que focaliza a organização das escolas e as práticas pedagógicas em seu interior, buscando estabelecer múltiplas relações. Além disso, há um pano de fundo conceitual básico, que permite delinear esse quadro. Esse quadro tem por perspectiva 
algumas consideraçóes do materialismo dialético, buscando os nexos entre o trabalho do professor e diferentes instâncias das escolas, das redes escolares e de inter-relaçôes de âmbito social, com possibilidades de compreensão cada vez mais alargadas, ou seja, mediante o pensamento, a reflexão e as relaçôes constantes da realidade visível.

Segundo essa abordagem, o real não é mero fato visível. Constrói-se, de fato, a realidade quando se estabelecem os nexos, as relaçóes, as conexóes. A realidade, portanto, não é só o visível, mas é, sobretudo, a resultante das análises feitas com a reflexão, com o pensamento que vai ao visível e volta sobre si mesmo, de modo constante, dialeticamente (LEFEBVRE, 1970).

Para realizar tais análises, recorre-se a diversos aportes teóricos, tanto de autores clássicos da área das Ciências Humanas e Sociais quanto de autores mais recentes, mas sempre pautados nos mais clássicos, da Sociologia, da Psicologia, da História e da Pedagogia; são autores que fundamentam os projetos e as análises dos dados. Com isso, há dedicação às diversas dimensôes, buscando encontrar essas possíveis relaçóes. Há dois conceitos também centrais para isso. Um deles é o da pluridimensionalidade, o outro é o da multidisciplinaridade, exatamente em razão do que foi dito: são muitas as dimensōes para se buscar os nexos, e são muitas as disciplinas com as quais é preciso operar buscando os campos conceituais para as análises, conforme se defende desde os anos de 1980 (MARIN, 2005).

Com isso, é possível compreender o que muitos autores nos ensinam - Elias (1994), Bourdieu (1998), Apple e Weis (1986) são alguns deles - ao dizerem, usarem ou ter usado o conceito de que o real é relacional. Então, se há uma concepção de que o real é relacional, aceitamos que a construção do objeto e toda a realização da pesquisa precisam ser relacionais, porque do contrário ela não apreende essa realidade. Só a análise constante é capaz de fazer os cruzamentos que permitam detectar a trama dessas relaçóes.

Vejamos um pequeno exemplo introdutório e estimulador. Se fecharmos os olhos e imaginarmo-nos em nossos trabalhos, vamos nos ver em algum lugar: uma sala de aula, um laboratório, uma quadra de esportes, cada um dentro de seu espaço de trabalho, coletando materiais, na frente da sala, falando com os alunos, passeando no meio dos alunos para ver se eles estáo fazendo as tarefas, atribuindo tarefas, explicando noçóes. Enfim, estaríamos fazendo uma série de atividades. Cada leitor pode ter diversificadas experiências e ser capaz de detectar outras açóes. 
Essa é a forma mais constante e tradicional de percepção sobre o trabalho docente dos professores. Assim, quando se fala de trabalho do professor, aparece na imaginação de muitos de nós, e mesmo dos que não estão lendo este texto, mas já passaram pela escola, ações que permitem identificar o que é ser um professor. Seja no Ensino Básico, seja na Educação Infantil ou no Ensino Superior. Esse realmente é o aspecto mais fundamental da vida da escola.

A escola foi feita para isso. Para que professores ensinem e os alunos aprendam. E os professores têm que fazer seu trabalho focalizando as questōes de aprendizagem dos seus alunos. Mas isso, em geral, é uma visão daquilo que tem maior aparência, aquilo que é mais visível para todos, ou seja, a sua especificidade. No entanto, ela não é só isso. A atividade docente é muito mais do que isso. Por que não se consegue imaginar o que mais contém o trabalho do professor? Ou o que mais está por detrás do, ou subjacente ao trabalho do professor? Este texto é uma mostra de respostas a partir dessa perspectiva.

\section{Sobre a vida e a formação dos professores}

O trabalho docente, gradativamente, ao longo das últimas seis décadas, passou a ser visto e relacionado a aspectos que náo são apenas o ensino propriamente dito. Há muitos outros aspectos, além dos apontados acima, ao se cuidar da aprendizagem das crianças e dos adolescentes, dos jovens. Há outros encargos e interferências paralelas. $\mathrm{O}$ trabalho docente, tal como consigo percebê-lo hoje, a partir dessa perspectiva teórica, foi se transformando ao longo das últimas décadas.

Em primeiro lugar, está uma questão que percebemos necessária, ao longo das análises das pesquisas, mas que, em muitos lugares, ela não está presente, pois não há busca de informaçốes sobre o professor, sua vida e formação. No decorrer dos nossos estudos, conseguimos juntar pistas para poder afirmar o seguinte: não é mais possível falar sobre o trabalho do professor se não tivermos informaçóes muito amplas, e ao mesmo tempo profundas, sobre o professor que executa essa função. É vital detectar quem é essa figura tão central da vida da escola; é preciso que o professor seja, de alguma forma, investigado para podermos compreender o trabalho que executa.

As pesquisas apontam com mais frequência, nos últimos anos, as questôes de gênero relacionadas ao trabalho docente. Ao longo da história, os estudos a respeito de professores e de seu trabalho demonstram que o que nós vivemos 
hoje resulta do fato de o magistério ter se tornado gradativamente uma profissão feminina. Aliás, os estudos demonstram, nos últimos anos, que ela nunca foi masculina (CABRERA; JIMENEZ, 1991, SPENCER, 2000), mas verdade é que a imensa maioria do corpo docente é do gênero feminino. Na pesquisa realizada em Santa Catarina (SHIROMA, 2011), obteve-se o dado de que $82 \%$ sấo mulheres, o que coincide com outro estudo realizado no Brasil: $81,3 \%$ (UNESCO, 2004). Há variaçóes, quando são analisadas as esferas de atuação, ou seja, Educação Infantil e Ensino Médio, por exemplo, pois neste último a proporção de homens é maior do que na atuaçáo com as crianças pequenas. Assim, analisar o trabalho docente relacionado às questóes de gênero nos leva a pensar e buscar compreender aspectos dessa característica tais como as expectativas de vida, os padróes de cultura no que tange aos comportamentos masculinos e femininos e, consequentemente, as interferências sobre o trabalho que tais agentes executam nas escolas.

Outras características começaram a ser verificadas nas pesquisas nos últimos anos, as quais não estavam táo presentes anteriormente nos estudos sobre os professores, sua formação e seu trabalho: são as informações que advêm da focalização da origem social dos professores. Certos dados da década de 1960 como, por exemplo, os de Pereira (1963), traziam essas características e opinióes sobre a carreira e a profissionalização, porém não estabelecendo relações diretas com o trabalho interno nas escolas. Posteriormente, principalmente na década de 1990, surgiram vários estudos denominados de "perfis de docentes", principalmente de escolas públicas. Em um estudo analítico e bibliográfico apresentado em 1992, Silva et al. (1992) finalizam o texto com as discussóes sobre formação de professores apontando que "[...] é urgente, pois, estudos que tratem, de maneira aprofundada, do professor enquanto ser concreto, alguém que vive num certo tempo, num certo lugar, em certas condiçôes"(SILVA, 1992, p. 15). E pode-se acrescentar: compará-los com professores de outras épocas para se detectar as mudanças a serem consideradas quanto às origens sociais, econômicas e culturais para que se tenha domínio das condiçóes esperadas ou a serem dadas a quem se dirige ao ensino. Assim, saber a origem da família atual; qual a constelação familiar; estado civil e características de seu (sua) companheiro (a); que profissóes exercem ou que ocupaçóes possuem as pessoas da família; qual a formação de tais pessoas de convívio na família, assim como identificar o local de moradia são fundamentais noçôes auxiliares para o desempenho da função docente e base para auxílios que possam ser fornecidos na formação inicial e continuada dos professores. 
Nessa direção, já se sabe, também, pelos estudos feitos com a perspectiva analítica presente em vários textos de Bourdieu (NOGUEIRA; CATANI, 1998), que os antecedentes precisam ser investigados no mínimo até os avós, pois a origem das pessoas, do ponto de vista social, cultural e econômico, é muito determinante para tudo o que se faz ou se pensa. Temos, no Estado de São Paulo, um levantamento bem grande a respeito da origem dos professores, e a imensa maioria deles é originária de populaçôes que tiveram pouquíssimo acesso à escola e aos bens culturais, por exemplo. Avós que não foram alfabetizados, que trabalharam duro na vida, mas que tiveram suas ocupações desempenhadas na zona rural ou em atividades pouco exigentes na esfera cultural simbólica. Pais que muitas vezes também não foram alfabetizados, mães que chegaram até um nível de escolaridade mínimo e não conseguiram avançar (BIANCHINI, 2007, 2011; SAMBUGARI, 2005; PENNA, 2011; PINHO, 2009; SANTOS, 2009). Tal perspectiva analítica demonstra que esses dados têm consequências para a formação dos professores e para o desempenho de sua função. Tais dados apontam que é preciso saber sobre isso. Por que é importante saber disso? Não é só para saber! Há que considerar como dado a informar políticas de formação, políticas culturais para tais agentes da educação e entender os dados relativos às dificuldades de recrutamento nos concursos. Pelos dados obtidos, parece urgente expandir políticas culturais que possam atingir os profissionais da educação de um modo que eles não tiveram nas suas infâncias, nas suas adolescências. Esses estudos têm identificado, em constelaçôes familiares, situações em que alguns irmáos conseguiram estabelecer o esquema de continuidade de estudos até o Ensino Superior, enquanto outros, principalmente os mais velhos, não conseguiram romper as barreiras sociais para isso, permanecendo nos empregos mais simples.

E qual é a formaçáo básica, superior inicial e continuada dos professores? Na pesquisa realizada em Santa Catarina (SHIROMA, 2011), há uma porcentagem grande de professores com formaçáo no Ensino Superior (84\%) e $52 \%$ com especialização, mestrado ou doutorado, mas essa não é a realidade do País, pois em 2004 eram $60 \%$ os que assim atuavam no Ensino Fundamental (UNESCO, 2004), mas os dados de 2009 nos informam que, de $1^{\underline{a}}$ a $4^{\underline{a}}$ séries, havia mais de $40 \%$ dos professores sem a formação superior, computados inclusive os leigos, e de 5a a $8^{a}$ séries, havia um contingente de cerca de $20 \%$ de professores atuantes sem nível superior ou na condição de leigos (GATTI; BARRETO, 2009). São dados fundamentais a serem considerados, quando 
pensamos nas condições para o exercício da docência, e têm relação direta com o preparo profissional advindo das açôes desenvolvidas quanto à natureza de todos esses cursos e do recrutamento dos profissionais.

Também há que se atentar para as experiências anteriores e atuais, porque os professores mais velhos e com mais tempo de exercício (a maioria em Santa Catarina) têm acúmulo de informação sobre o próprio trabalho; isso é formação em serviço, é aprendizagem que vem das experiências vividas e que às vezes auxiliam, às vezes não, em seu trabalho. É preciso entender também as suas manifestações sobre esses dados, que são importantes pontos de reflexão no interior das escolas.

Assim, é possível identificar que tais aspectos dizem respeito à pessoa do professor, são importantes auxiliares sobre a vida e a formação para compreensão do trabalho que esse agente desempenha nas escolas. É algo que não é mais possível ignorar, tanto ao se formar professores e ao investigar o trabalho do professor - porque esse trabalho depende de todos esses aspectos - quanto ao desempenhar as atividades cotidianas nas escolas, analisando o que ali ocorre por eles mesmos e seus superiores. Trata-se de suas vidas, experiências, formaçōes contínuas, de vidas pregressas às escolas, vidas infantis e adolescentes, e os acessos que tiveram a uma série de exigências que as escolas lhes apresentam hoje.

\section{O trabalho docente}

A opçáo, neste texto, foi a de centralmente analisar o trabalho docente via açôes políticas educacionais, e estou tomando a Lei de Diretrizes e Bases da Educação Nacional de 1996 (SAVIANI, 1997), nossa última legislação geral que traz sérias consequências para as escolas e para o trabalho docente. Leis anteriores também interferiram como, por exemplo, a Lei de 1971, ou seja, a 5.692 (BRASIL, 1971), que teve consequências importantes para o trabalho do professor na medida em que organizou o ensino em oito anos, definindo a organização curricular por atividades, áreas de estudo e disciplinas, proposta que significou novas definiçóes formais para o trabalho do professor do ponto de vista didático-pedagógico. Essas definições vieram esmaecendo ao longo do tempo e não alteraram de modo significativo as escolas, mas tomo a legislação que atualmente nos rege para a compreensão do que vem ocorrendo com o trabalho docente, posto que as insistências têm sido grandes, e os controles, também. 
É importante que se faça uma chamada sobre os pontos a serem observados daqui por diante, pois as escolas possuem duas faces organizativas. De um lado, temos a Lei interferindo na organização das escolas com conjunto de orientaçóes e prescriçóes para atender aos objetivos propostos para a educação. De outro lado, temos a mesma Lei que define vários princípios para a educação nacional caracterizando modos de organizar o trabalho escolar com a divisão do trabalho a partir das funçóes atribuídas aos agentes das redes, segundo Oliveira (2010). Ambas as faces dessa organização estão muito entrelaçadas, interferindose mutuamente, com bases fornecidas pela legislação para as modificaçóes desejadas, pois, segundo Lima (2008), todas as organizaçóes possuem objetivos, preferências organizacionais, tecnologias e processos organizacionais. No caso brasileiro, identificamos bases que têm em vista a descentralização e a autonomia em novas formas de organizaçáo e gestáo das escolas e das redes. Além disso, temos tido, junto com tais regulamentaçóes, todas as decorrências múltiplas ao longo dos anos 2000 a respeito da formação dos agentes educacionais, isto é, a dos professores e dos demais com as Diretrizes Curriculares dos cursos de Licenciatura e de Pedagogia.

A Figura 1 nos permite certa visão da organização do trabalho das escolas a partir das açôes políticas de educação.

Figura 1 - Aspectos relativos à organização do trabalho nas escolas

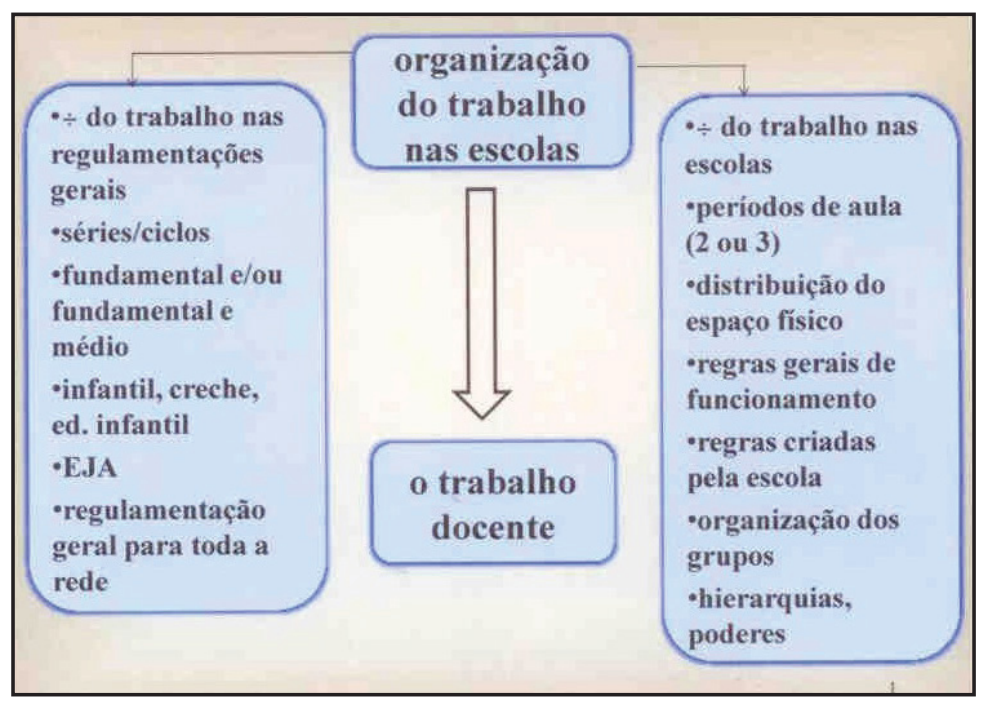

Fonte: Elaborada pela autora. 
Verifica-se, assim, que há conjunto de medidas e decisões que vão se desdobrando da Lei Federal de 1996 (BRASIL, 1996) para outras instâncias e gradativamente multiplicadas pelo País. Junto com isso, temos, de um lado, os controles, que cada vez mais estáo crescendo e disseminados, e a definiçáo das condições, pois as condições de trabalho dependem desse conjunto de regulamentaçôes.

Do lado esquerdo da Figura 1, temos diversos aspectos da organizaçáo do trabalho das escolas, sempre lembrando que estamos em um sistema capitalista, com divisão de trabalho acentuadíssima, a partir de regulamentações gerais com as redes criando seus desdobramentos e variaçôes. Cada rede escolar tem especificidades, porém há generalidades no que se refere a cargos e funçôes: diretor, vice-diretor, coordenador pedagógico, técnicos, assistentes administrativos e professores, que também têm certas atribuições de trabalho no conjunto.

Entre as regulamentaçóes gerais, a legislação apresenta a possibilidade de as escolas organizarem o trabalho em séries ou ciclos. Como se trata de "possibilidade", algumas redes optaram por se organizar em ciclos, outras permaneceram com a tradicional organização em séries. Essa, porém, não é uma simples medida administrativa, porque implica alteraçôes profundas nos esquemas de trabalhos dos professores, que, como já disse, têm uma tradição de trabalho por série, com rotinas de passagem entre uma e outra ao longo da escolaridade, com aprovaçóes e reprovaçôes. As redes que implantaram os ciclos adotaram, simultaneamente, o regime de progressão contínua, ou seja, a nãoreprovação entre uma série e outra. Essas medidas trazem muitas consequências para os professores, desde o planejamento de conteúdos, de atividades, até acompanhamentos, alterando-se substantivamente os esquemas de trabalho docente no interior das escolas.

A definição de âmbitos escolares a serem atendidos pelas escolas em relação à população estudantil é outro foco nem sempre presente nas análises de consequências para o trabalho dos professores, ou seja, se a escola atenderá a todo o Fundamental, se atenderá ao Fundamental e ao Médio, se atenderá à Educação Infantil (creche ou não) e à Educação de Jovens e Adultos. Essas são decisōes que implicam organizaçóes diferenciadas para o trabalho de todos os que estão no interior das escolas e de que modo as tarefas serão distribuídas por aqueles que ali trabalham. 
Do lado direito da mesma Figura, encontram-se vários desdobramentos da legislação vista anteriormente, mas agora já no interior das escolas, com novos desdobramentos, pois, embora haja regulamentação para as redes como um todo, há consequências diferenciadas para as unidades escolares e para os professores. Como ocorre essa divisão interna nas escolas é objeto desta compreensão sobre a docência, pois os estudos e pesquisas têm mostrado que há variaçóes na divisáo de trabalho internamente segundo critérios variados. Quem são os professores que ficam com as turmas mais difíceis, quem são os professores que assumem as turmas do primeiro ano? Há estudos que relatam e analisam que os experientes querem escolher as turmas em primeiro lugar, os mais antigos escolhem antes dos mais novos, ocasionando o fato de os iniciantes ficarem com as turmas dos repetentes ou as turmas de alfabetização, principalmente com a implantação da escola de nove anos com as crianças de seis anos. Os professores sofrem processos de socialização apreendendo tais regras, mesmo que já sejam experientes, mas são tratados como novatos ao mudar de escola ou de rede de ensino (FERREIRINHO, 2004). Enfim, a divisão de trabalho na escola depende, em geral, de uma hierarquia existente dentro de cada escola.

A definição de número e duração dos períodos de aula - se são dois ou três períodos - faz toda a diferença para o conjunto das informaçóes que os professores possuem para se organizarem e organizarem o trabalho dos alunos, assim como a distribuiçấo das condiçóes físicas da escola. Definir quem vai ficar com a sala de frente para a rua com o barulho intenso ou ao lado da quadra de esportes, para qual turma vai a sala mais gostosa ou a menos quente que não recebe sol... São muitas as decisóes nessa esfera a condicionar a realizaçáo das atividades pedagógicas.

Essas decisões nos levam a considerar a existência de grupos organizados dentro das escolas, com suas hierarquias, com seus poderes. Existe um poder oficial, a hierarquia de direito cumprida pelo diretor e pelo vice-diretor, mas na dinâmica diária há a organizaçấo dos agentes com a presença daqueles que se destacam, que exercem lideranças, podendo ser identificados nas diferentes circunstâncias, como se formam, em base de quais critérios, quais são as relaçôes que se estabelecem (SANTOS, 2011).

As regras gerais de funcionamento das escolas são definidas em outras instâncias, regionais ou estaduais, mas as escolas também criam suas próprias regras, às vezes interpretando, outras vezes alterando o que vem definido, outras vezes, ainda, criando detalhes não regulamentados por medidas genéricas. A organizaçáo do trabalho da escola tem sido focalizada nos estudos segundo as 
noções divulgadas por Lima (2008). Esse autor nos informa sobre diversos tipos de regras não formais ou informais compondo a ordem anárquica quando comparada com as regras formais que compóem a ordem burocrática. Estas geralmente são gerais e veiculadas em documentos advindos das instâncias superiores para toda a rede a que pertencem as escolas. As informais e não formais são criadas pelas escolas, e a diferença está no seu grau de estruturação. Alguns estudos feitos em escolas demonstram diversas formas de criação dessas regras para nortear diferentes tipos de atividade. Um dos exemplos está no estudo sobre absenteísmo docente, em que o agente que controla o recreio das crianças também controla a chegada ou não dos professores, definindo a substituição de professores faltosos, quais os critérios utilizados por esse agente nessas circunstâncias, se os alunos são dispensados ou se eles ficam no pátio, com aula vaga (GESQUI, 2008). Trata-se de uma regra criada pela própria escola, ou seja, uma regra não formal, com certa estruturaçáo, embora nem sempre seja escrita, mas é de conhecimento de toda a escola e náo atende apenas a uma circunstância, mas ao funcionamento diário da escola.

Iniciamos, aqui, uma análise da organização da escola pelos Parâmetros Curriculares Nacionais (PCNs) (BRASIL, 1997) a partir da Figura 2.

Figura 2 - Aspectos relativos à organização das escolas: os Parâmetros Curriculares Nacionais

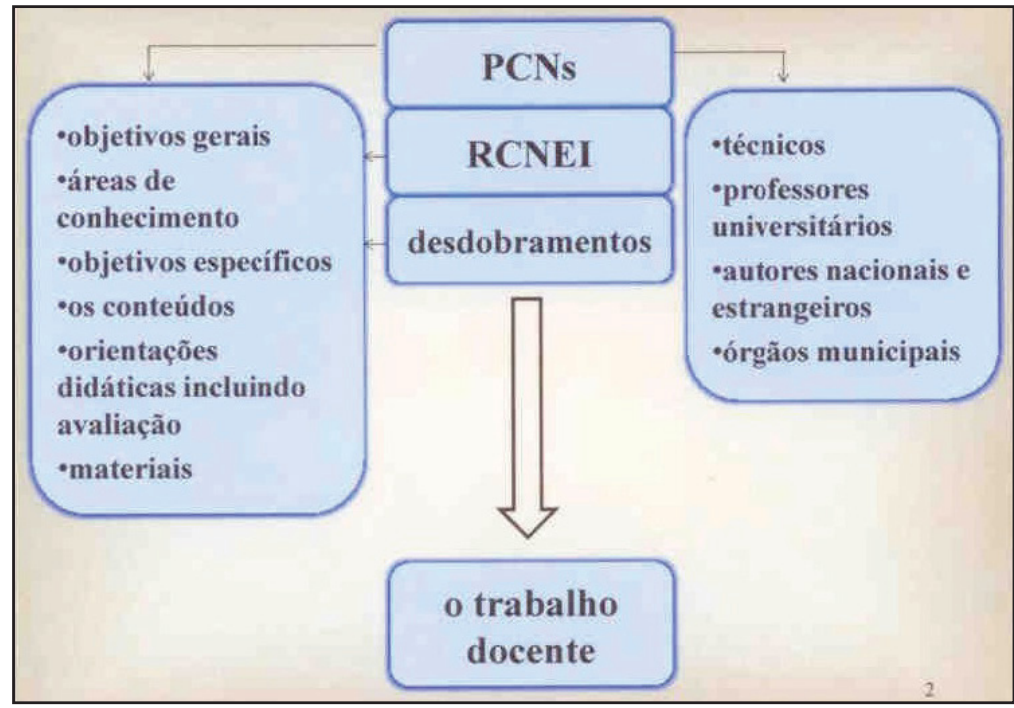

Fonte: Elaborada pela autora. 
Quando partimos dos PCNs (BRASIL, 1997), o que equivale para os demais referenciais ou diretrizes curriculares, há sempre um esquema geral operacional, e sua análise nos leva a perceber inúmeras definiçôes para a organização escolar e, consequentemente, para o trabalho dos professores. Analisando a Figura 2, pelo seu lado esquerdo, referenciada nos PCNs da Educaçâo Fundamental, séries iniciais (BRASIL, 1997), verifica-se que são definidos objetivos gerais para todas as áreas de conhecimento, igualmente listadas e que devem compor o currículo das escolas do Ensino Fundamental, para entáo, cada volume (nove áreas, incluindo a dos temas transversais) tratar da caracterização dessas áreas, suas concepçóes e o significado da sua aprendizagem na escola. A seguir, definem os objetivos gerais da área para o Ensino Fundamental, definem os conteúdos com seus eixos e sua sequência, orientaçôes didáticas incluindo avaliação, materiais e fontes onde encontrar ajudas para o trabalho. Como se pode vislumbrar, é um grande conjunto de delineamentos. Estão postos como parâmetros, porém sabe-se hoje, muito bem, que eles são cobrados posteriormente, pois desde a criação da Prova do Sistema de Avaliação Educacional do Brasil (SAEB) em 1995, há constantes avaliaçóes, sobretudo em Língua Portuguesa e Matemática, pautadas nessas definiçôes que vieram em 1997, e a expansão dessas avaliaçôes externas para os Estados e municípios nos anos subsequentes.

Do outro lado da Figura 2, temos pessoas, técnicos do Ministério da Educação, professores universitários, autores nacionais e estrangeiros que disseminam e fundamentam os textos e dão consultorias, órgãos estaduais e municipais que utilizam essas referências, todos responsáveis diretamente por tais orientaçôes para os professores.

Ao avançar a análise, temos a Figura 3 com alguns elementos para focalizar de modo ainda mais específico a organização da escola no que tange às condiçôes pedagógicas nas instituiçốes.

Na Figura 3, começamos a verificar a organização escolar focalizando as turmas de alunos. Como são compostas as turmas? A maneira mais constante é a de buscar a homogeneidade como um princípio que tem perpassado a escola de ponta a ponta. Mas, nos últimos anos, esse princípio vem sendo posto em questão de modos diversos: há as ações políticas de inclusão interpretadas como formas de inserir nas escolas regulares as crianças portadoras de deficiência, mas não se reportando às demais diferenças. As tradicionais classificações de turmas em $\mathrm{A}, \mathrm{B}, \mathrm{C}$ ou 1, 2, 3 são questionadas para inverter o alfabeto de modo a não 
caracterizar as turmas como fortes, médias ou fracas, pois o questionamento implica que os professores possam trabalhar, de fato, com a heterogeneidade que as individualidades portam. E, como consequência, resta a atribuiçẫo dessas turmas aos professores, como parte da divisão do trabalho escolar, fato que perpassa pelas mesmas questóes anteriormente aventadas para as séries iniciais do Ensino Fundamental.

Figura 3 - Aspectos diversos da organização interna das escolas

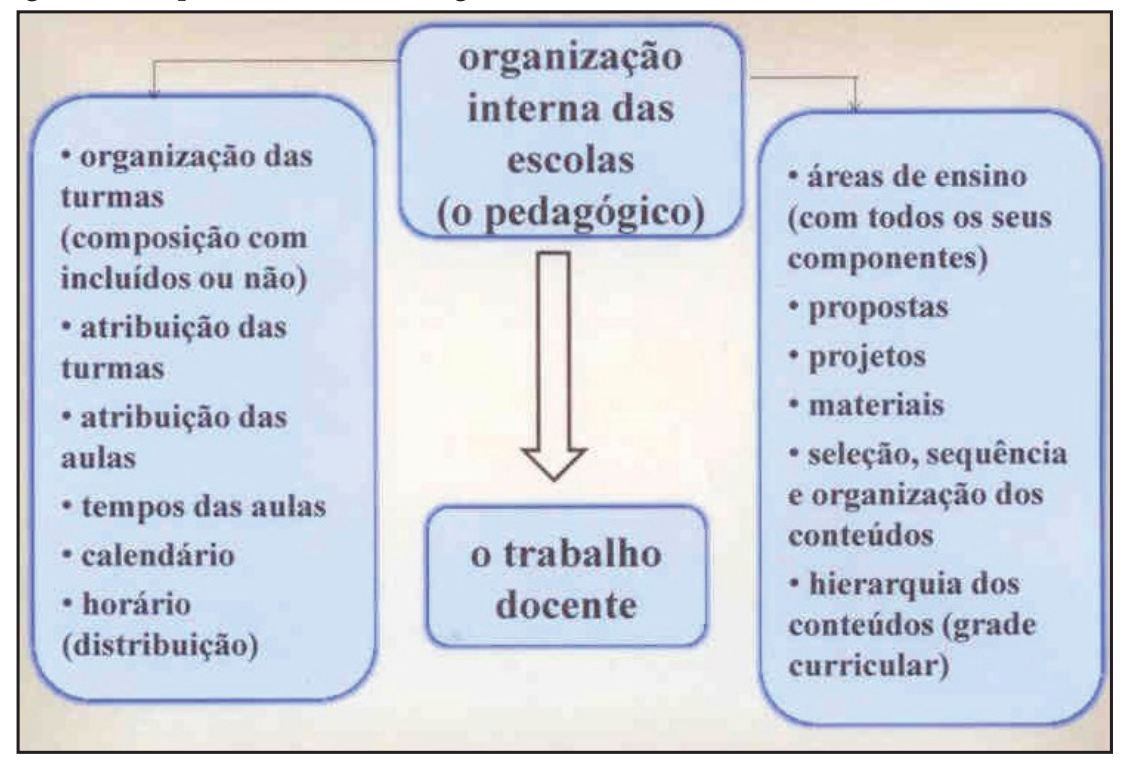

Fonte: Elaborada pela autora.

Do mesmo modo, a atribuição das aulas aos professores que atuam nas séries finais do Ensino Fundamental e no Ensino Médio está sujeita a regras gerais formais, legais, mas também a regras não formais mediante os critérios adotados pelas escolas ou pelas redes. Há mudanças constantes que geram a possibilidade de manipulaçóes, criando alteraçóes nos esquemas do trabalho escolar de um ano para outro, com consequências para os aspectos pedagógicos.

Alguns aspectos relacionados ao tempo no interior da escola são cruciais regulamentações formais e não formais. Se a organização do trabalho escolar se faz por aulas simples, de 40 ou 50 minutos, se são possíveis as aulas duplas, são decisóes que condicionam as características pedagógicas dos diferentes 
componentes curriculares. Há certos componentes em que as crianças ou jovens se beneficiariam mais de aulas duplas do que de aulas simples como, por exemplo, as aulas de Artes, em que os professores consideram benéfico ficar mais tempo, de modo que os trabalhos possam avançar mais e não serem entrecortados.

A regulamentação dos horários de funcionamento quanto ao calendário e aos horários de início e final de períodos de aulas são decisóes de organização do trabalho escolar genéricas para toda a rede, porém a organização dos componentes dentro desses períodos decorre de decisão das escolas. É o "famoso" trabalho de organizar o horário das aulas em que há certos professores beneficiados e outros prejudicados, pois, se há uma notícia nas escolas da qual ninguém gosta, é a de ficar com aulas nas sextas-feiras à noite! Certamente, um período em que os professores e alunos já estão cansados, principalmente para os que estudam ou lecionam à noite. Assim, há influências diretas da organização do trabalho sobre os aspectos pedagógicos em dias e horas mais propícios ou preferidos pelos professores, pois exigem menos empenho para deter a atenção dos alunos, enquanto em outros períodos há mais exigência de variação nos procedimentos e nas tarefas de modo a que a aprendizagem possa ser garantida.

Do lado direito da Figura 3, encontramos outros aspectos que decorrem, sobretudo, de decisões internas das escolas quanto aos aspectos pedagógicos, mas todas elas emanam, de certa forma, das decisóes vistas anteriormente, como por exemplo, alguns detalhes analisados sobre os PCNs (BRASIL, 1997), nos quais constam os parâmetros para as escolas. Iniciamos verificando que as escolas precisam fornecer a todos os alunos os componentes curriculares obrigatórios, portanto temos uma organização escolar definida. $\mathrm{O}$ que não temos, genericamente colocada, é a distribuição temporal deles, pois há, regionalmente, possibilidade da organização do trabalho escolar com definição de quantas horas-aula cada componente possuirá a cada ano. E sempre há predomínio de aulas para Português e Matemática, o que acarreta uma das características de hierarquia nesses componentes em face, por exemplo, de Artes ou Educação Física.

As escolas têm a incumbência legal de organizar os seus projetos, suas propostas de trabalho. É o momento de a escola se definir pelo trabalho por disciplinas ou por áreas, com fronteiras bem marcadas ou não. É na elaboração do projeto pedagógico das escolas que está a possibilidade de debater todos os elementos que nortearáo, de fato, bem proximamente, o trabalho dos 
professores, pois ele deve ser o mapeamento do trajeto de alguns anos para a formação do alunado. Quais são os projetos de ensino, qual a seleção, sequência e organização dos conteúdos de cada componente curricular para cada ano a ser cursado pelos alunos? De onde partem cognitivamente os alunos e aonde devem chegar? O que se pretende com esse processo? Quais as relaçóes entre os diferentes componentes? É a mais fundamental parte de definição do trabalho dos professores ao decidir, afinal, para que serve cada escola na vida de todos os que ali estão. Há, nessa esfera, intensa relação entre a divisão de trabalho escolar, com as tarefas a serem cumpridas, e a organizaçáo das condiçóes da escola para atender aos conteúdos, procedimentos, materiais e avaliaçóes a partir dos PCNs (BRASIL, 1997), pois ali estão os pontos já citados, mas há a partir deles muitos desdobramentos políticos, como por exemplo, planos governamentais de alteraçáo de distribuição de materiais para as escolas (livros, kits, computadores, entre outros), seguindo o previsto nesses parâmetros.

Aí entra a gestấo das escolas. Na Figura 4, estáo diversos elementos a serem analisados sobre as questóes da gestão.

Figura 4 - Aspectos da gestão escolar

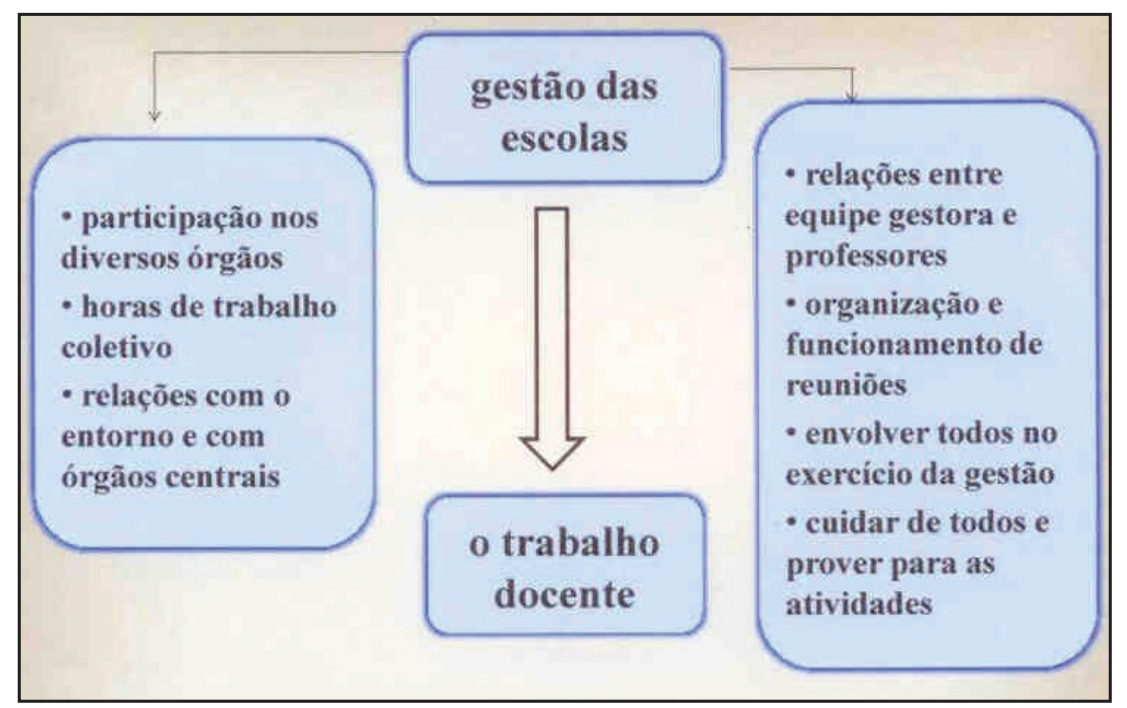

Fonte: Elaborada pela autora. 
A legislação federal já previu inúmeros desses elementos, ou seja, já existe regulamentação sobre a criação de diversos órgãos e horas de trabalho coletivo no interior das escolas como, por exemplo, Conselho de Escola, Associação de Pais e Mestres, Grêmio Estudantil, Horas de Trabalho Pedagógico nas jornadas que são auxiliares da gestão escolar. Para os professores, há consequências, considerando que a sua participação está prevista em quase todos eles, além de prever atividades de relaçóes com o entorno da escola, com a família, visando a uma maior integração.

Assim, tais exigências implicam as características constantes do lado direito da Figura 4, ou seja, relaçóes entre equipes de professores, organização e funcionamento de reunióes, cuidar de detalhes para prover de modo que as atividades possam ser realizadas a contento. São muitos os desdobramentos, pois há boa parte do tempo dos professores envolvidos com tais atividades. Além dessas atividades e das regulares das aulas, há outras sazonais, não regulamentadas oficialmente, mas que são da cultura das escolas, como por exemplo, festas juninas, festa do sorvete, festa da primavera, ou seja, oportunidades em que muitos professores desempenham inúmeras açóes, compondo parte da divisão de tarefas dos agentes.

Figura 5 - Aspectos relativos a condiçôes de trabalho

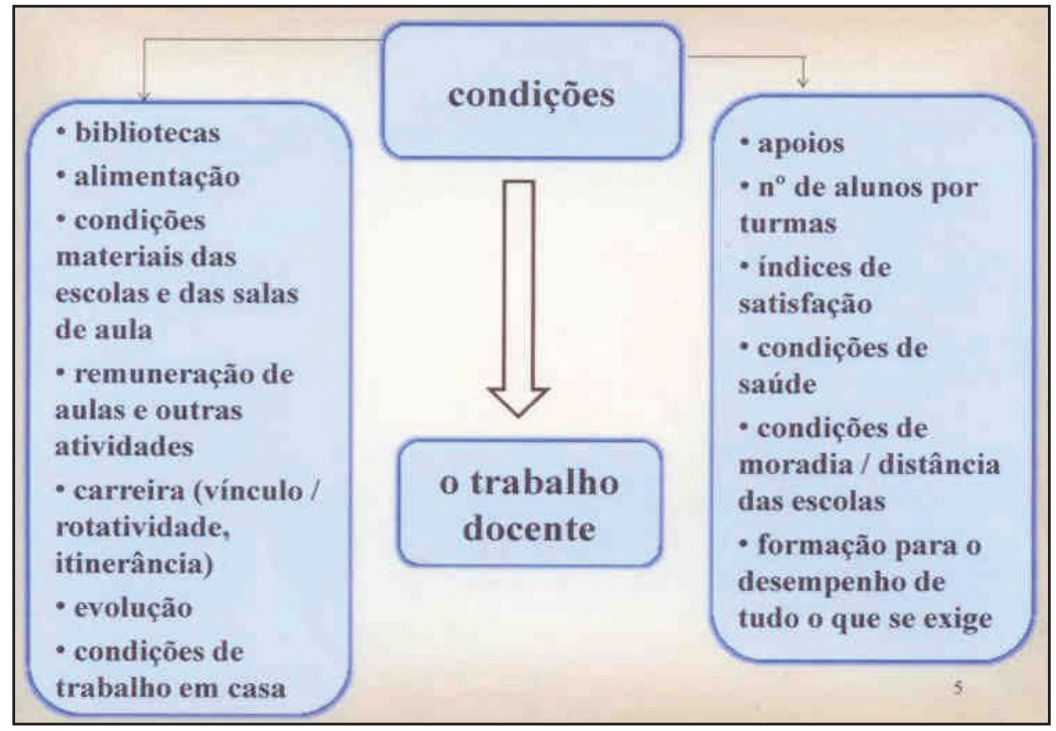

Fonte: Elaborada pela autora. 
Parte ainda da gestão das escolas refere-se ao conteúdo da Figura 5, envolvendo diferentes instâncias para que a essencial atividade pedagógica de qualidade aconteça. Trata-se das condições para as atividades de professores e alunos. Do lado esquerdo, estáo implicaçôes de condiçôes de natureza física e social para o desempenho da função: bibliotecas; alimentação; condiçôes materiais das escolas e das salas de aula; remuneração de aulas e outras atividades; carreira (vínculo/rotatividade/itinerância/evolução); condiçôes de trabalho em casa em face dos inúmeros afazeres das mulheres e de sua condição socioeconômica.

Do lado direito da Figura 5, há condiçôes de outra natureza, algumas delas decorrentes de regulamentaçóes, outras como características de vida pessoal e familiar, e outras, ainda, como consequência de decisões internas ou de buscas de ajudas: apoios; número de alunos por turma; número de turmas; índices de satisfação no interior da escola; condiçôes de saúde; condiçốes de moradia/distância das escolas; formação para o desempenho de tudo o que se exige, tanto para a divisão do trabalho escolar quanto para a organização qualitativa da escola.

\section{Considerações finais}

Essa é uma separação didática, é explicativa, analítica, exemplificadora. Partimos de consideraçóes sobre a Lei de Diretrizes e Bases da Educaçáo Nacional (BRASIL, 1996) como estipuladora ou fornecedora de possibilidades para regulamentar a vida das escolas e de seus agentes, e fomos desdobrando, em vários aspectos e instâncias, as decorrências para a docência.

O cruzamento dessas informaçôes é vital. Muitas vezes, temos esse conjunto na íntegra ou parte dele, mas ele fica partido, segmentado. Ao cruzar essas informaçôes é que se obtêm os nexos, é quando se usa o referencial teórico, agora para as análises e para as reflexóes. Mas isso também não é aleatório: há questôes a orientar tal cruzamento, pois de outro modo não sabemos qual a informação a ser obtida e como operar com ela. Esse é o trabalho mais decisivo da pesquisa, é o da obtenção de dados analíticos a partir de muitos dados descritivos, buscando as relações que permitam a compreensão para além das aparências.

Essa é uma pequena amostra das relaçóes que fazem com que a concepção do trabalho docente fique sempre denominada de complexa, mas que não se 
sabe bem como explicitar essa complexidade. Verificam-se, no trabalho dos professores, essas pressōes, essas exigências que são feitas, sem a explicitação de suas origens e sem saber das suas condiçôes para executá-las.

Estão presentes exigências ou decisôes relacionadas à organização de todo o trabalho a ser feito nas escolas e outras que se referem à organização da escola para as açóes pedagógicas, para que a educação de fato aconteça. Esse conjunto está ligado às insatisfaçóes que os professores têm enfrentado, ou seja, trata-se de um fenômeno denominado intensificação do trabalho docente, de um lado, e de outro está ligado à busca do profissionalismo, ambos perpassados pelas questóes dos controles internos e externos de desempenho. A intensificação tem sido abordada por diferentes autores desde a década de 1980, sobretudo pelas perspectivas analíticas sociológicas. Apple (1995), em um conjunto de estudos divulgados nos Estados Unidos em 1986, já analisava a sobrecarga crescente de trabalho dos professores mascarando-o de profissionalismo. $\mathrm{O}$ conjunto das exigências que os sobrecarregam, os prazos definidos, a prestação de contas das tarefas levam à preocupação com o não cumprir das tarefas e, consequentemente, ao sentimento de ineficiência e/ou incompetência, certamente ligados a questóes de profissionalismo. Outros autores igualmente analisam essas situaçôes apontando a intensificação e tecnização do trabalho como um crescente envolvimento com as atividades administrativas e o afastamento da tarefa específica da docência (LAWN; OZGA, 1991), além de apontarem a necessidade de estudos que analisem como essas mudanças organizativas afetam, de outros modos, o ensino. Hargreaves (1998), por sua vez, a partir de pesquisas empíricas, aponta que o perfeccionismo buscado nos processos nesses tempos de mudança implica questôes de tempo dos docentes em que a intensificaçáo, por sua vez, provoca a redução na qualidade dos serviços, condiçôes não disponíveis na formação dos professores exigindo a diversificação constante de seus saberes.

Boa parte do que foi apontado nos diversos itens das figuras constitui esse acúmulo e esses problemas referidos pelos autores como decorrência das açóes políticas a causar impactos no trabalho dos professores, sempre necessários de novas investigaçóes. 


\section{REFERÊNCIAS}

APPLE, Michael W. Controlando o trabalho docente. In: APPLE, Michael W. Trabalho docente e textos: economia política das relações de classe e de gênero em educação. Porto Alegre, Artmed, 1995, p. 31-52.

APPLE, Michael W.; WEIS, Lois. Vendo a educação de forma relacional: classe e cultura na sociologia do conhecimento escolar. Educação \& realidade, Porto Alegre, v. 1, n. 1, p. 19-33, jan./jun. 1986.

BIANCHINI, Noemi. As ausências de conhecimentos manifestos na formação de professoras-alunas de Curso Normal Superior. 2005. 203 f. Dissertação (Mestrado em Educação Escolar) - Universidade Estadual Paulista, Araraquara, 2005.

BIANCHINI, Noemi. Distinçâao: efeito de trajetória social. 2011. 159 f. Tese (Doutorado em Educação: História, Política, Sociedade) - Pontifícia Universidade Católica de São Paulo, São Paulo, 2011.

BOURDIEU, Pierre. Introdução a uma sociologia reflexiva. In: BOURDIEU, Pierre. O poder simbólico. Bertrand Brasil: Rio de Janeiro, 1998, p. 17-58.

BRASIL. Lei no 5.692, de 12 de agosto de 1971. Fixa Diretrizes e Bases para o ensino de $1^{\circ}$ e $2^{\circ}$ graus, e dá outras providências. Diário Oficial da União. Brasília, DF, 12 ago. 1971.

BRASIL. Lei no 9.394, de 20 de dezembro de 1996. Estabelece as diretrizes e bases da educação nacional. Diário Oficial da União. Brasília, DF, 23 dez. 1997.

BRASIL. Ministério da Educação. Secretaria de Educação Fundamental. Parâmetros Curriculares Nacionais: ensino de 1ํa a $4^{\underline{a}}$ série. Brasília, DF, 1997.

CABRERA, Blas; JIMENEZ, Marta. Quem são e que fazem os docentes? Sobre o "conhecimento" sociológico do professorado. Teoria \& Educação, Porto Alegre, n. 4, 1991, p. 190-213.

ELIAS, Norbert. A sociedade dos individuos. Rio de Janeiro: Zahar, 1994.

FERREIRINHO, Viviane Canecchio. Começar de novo: práticas de socializaçáo do professor em início de carreira. 2004. 220 f. Dissertaçáo 
(Mestrado em Educação: História, Política, Sociedade) - Pontifícia Universidade Católica de São Paulo, São Paulo, 2004.

GESQUI, Luiz Carlos. Organizaçâo da escola, absenteísmo docente, discente e rendimento escolar. 2008.147 f. Dissertaçáo (Mestrado em Educação: História, Política, Sociedade) - Pontifícia Universidade Católica de São Paulo, São Paulo, 2008.

HARGREAVES, Andy. Intensificação: o trabalho dos professores. Melhor ou pior? In: HARGREAVES, Andy. Os professores em tempos de mudança: o trabalho e a cultura na idade pós-moderna. Lisboa: McGrawHill, 1998, p. 131-158.

LAWN, Martin; OZGA, Jenny. O trabalho docente: interpretando o processo de trabalho do ensino. Teoria \& Educação, Porto Alegre, n. 4, p. 140-157, 1991.

LEFEBVRE, Henri. Lógica formal, lógica dialéctica. Madrid: Siglo Ventiuno de España, 1970.

LIMA, Licínio C. A escola como organização educativa: uma abordagem sociológica. São Paulo: Cortez, 2008.

MARIN, Alda Junqueira. O trabalho docente: núcleo de perspectiva globalizadora de estudos sobre ensino. In: MARIN, Alda Junqueira (Coord.). Didática e Trabalho Docente. Araraquara: Junqueira \& Marin, 2005, p. 30-56.

MARIN, Alda Junqueira; BUENO, José Geraldo Silveira; SAMPAIO, Maria das Mercês Ferreira. Escola como objeto de estudo nos trabalhos acadêmicos brasileiros: 1981-1998. Cadernos de Pesquisa, São Paulo, v. 35, n. 124, set./ dez. 2005, p. 171-199.

MARIN, Alda Junqueira; BUENO, José Geraldo Silveira. La investigación sobre trabajo docente en Brasil: balance sobre disertaciones y tesis 1987/2006. In: OLIVEIRA, Dalila Andrade; FELDFEBER, Myriam (Comps.). Nuevas regulaciones educativas en América Latina: políticas y procesos del trabajo docente. Lima: Fondo Editorial UCH, 2010, p. 215238.

NOGUEIRA, Maria Alice; CATANI, Afrânio (Org.). Pierre Bourdieu: escritos de Educação. Petrópolis: Vozes, 1998. 
OLIVEIRA, Dalila Andrade. Mudanças na organização e na gestão do trabalho na escola. In: OLIVEIRA, Dalila A.; ROSAR, Maria de Fatima F. Política e gestão da educação. Belo Horizonte: Autêntica, 2010, p. 127-146.

PENNA, Marieta Gouvêa de Oliveira. Exercício docente: posiçóes sociais e condiçôes de vida e trabalho de professores. Araraquara: Junqueira \& Marin, 2011.

PEREIRA, Luís. O professor primário metropolitano. Rio de Janeiro: Instituto Nacional de Estudos Pedagógicos. Centro Brasileiro de Pesquisas Educacionais, 1963.

PINHO, Fernanda Mello Rezende. Origem, formação e representaçôes sobre o exercício da profissáo de professores de Educação Infantil. 2009. 141 f. Dissertaçãoo (Mestrado em Educação: História, Política, Sociedade) Pontifícia Universidade Católica de São Paulo, São Paulo, 2009.

SAMBUGARI, Márcia Regina do Nascimento. Socialização de professores em atividades de educação continuada. 2005.166 f. Dissertação (Mestrado em Educação Escolar) - Universidade Estadual Paulista, Araraquara, 2005.

SANTOS, Lívia Freitas dos. O concurso público no processo de profissionalização docente: análise dos concursos realizados pela Prefeitura Municipal de São Paulo (2004 a 2009) e perfil dos professores de História aprovados. 2009. 167 f. Dissertação (Mestrado em Educação: História, Política, Sociedade) - Pontifícia Universidade Católica de São Paulo, São Paulo, 2009.

SANTOS, Silmar Leila dos. Hierarquias e poderes no cotidiano escolar: da organização burocrática à organização de pessoas. 2011. 175 f. Tese (Doutorado em Educação: História, Política, Sociedade) - Pontifícia Universidade Católica de São Paulo, São Paulo, 2011.

SAVIANI, Dermeval. A nova lei da educação. Campinas: Autores Associados, 1997.

SHIROMA, Eneida (Coord.) Seminário Estadual: O trabalho docente na Educação Básica em Santa Catarina. Florianópolis, 2011. mimeo.

SILVA, Rose Neubauer et al. Formação de professores no Brasil: um estudo analítico e bibliográfico. In: SEMINÁRIO de Formação de Professores para a Educação Básica: experiências no Brasil e na França. Brasília, DF, 1992. mimeo. 
SPENCER, Dee Ann. La enseñanza como un trabajo femenino. In: BIDDLE, Bruce J.; GOOD, Thomas L.; GOODSON, Ivor F. La enseñanza y los profesores: la profesión de enseñar. Barcelona: Paidós, 2000, p. 167-218.

UNESCO. O perfil dos professores brasileiros: o que fazem, o que pensam, o que almejam. São Paulo: Moderna, 2004. 


\section{Acciones de políticas Educational policy action educativas e impactos sobre and impacts on the work of el trabajo docente teaching}

\section{Resumen}

El texto presenta un análisis sobre la Ley de Directrizes y Bases de La Educación Nacional y desplegamientos que exigen muchas transformaciones para las escuelas y para el trabajo docente. Afirma los profesores como sujetos a muchas acciones de políticas educativas y señala la necesidad de expansión de comprensión con relaciones entre diversos aspectos tanto para las investigaciones cuanto para la formación y función docente en las escuelas. Para esto examina puntos de la ley sobre organización del trabajo y la organización de las escuelas y sus impactos sobre el trabajo docente articulando con datos de investigaciones sobre la realidad actual.

Palavras claves: Reglas de las políticas educativas. Organización del trabajo docente. Problemática del magistério

\section{Abstract}

This text analyses the National Educational Guidelines and Bases Law and its consequences, which involve various changes for schools and the work of teachers. It affirms this agent as the subject of political actions in education and indicates the need for a broad understanding in relation to research, teacher education and the work of teachers in schools. It examines the organization of their work and of the school found in the law and its impacts on the work of teachers, articulated with data from current studies.

Keywords: Educational policy guidelines. Organization of the work of teachers. The problematic of teaching.

Alda Junqueira Marin

E-mail: aldamarin@pucsp.br

Recebido em: 9/3/2012

Versão final recebida em: 21/6/2012

Aprovado em: 22/6/2012 